\title{
Cumhuriyet Neslinin İnşasında Sosyoloji ve Pedagoji Üzerine Öncü Bir Eser: Hasan Zeynettin Akkök ve Kitabı: Millî Pedagoji ve Türk İçtimaiyatı
}

\section{Dr.Yeliz Okay}

Gelis tarihi: 16.07 .2019

Kabul tarihi: 22.07.2019

\section{Atıf bilgisi:}

Uluslararası Bilimsel Araștırmalar Dergisi (IBAD)

Cilt: $4 \quad$ Sayı: 2

Sayfa: 453-459 Yıl: 2019

Dönem: Yaz

This article was checked by Turnitin. Similarity Index 05\%

${ }^{1}$ Türkiye, yelizakinokay@gmail.com ORCID ID 0000-0001-8868-9436

* Sorumlu yazar
ÖZ

Millî toplum ve millî kimlik düşüncesinin etrafinda belirginleşen Cumhuriyet dönemi eğitim anlayışı, sosyokültürel temellerin üzerinde, bilimsel olarak Sosyoloji ve Pedagojinin ilkeleri ile şekillenmiştir. Cumhuriyet Dönemi, Ziya Gökalp'ın millî kimlik ve millî kültür çatısı altında ulus bilinci ile șekillenmis bir halk idealini doktrin olarak biçimlendirmesi millî eğitimin esaslarının da bu doğrultuda tespitini sağlamıștır. Millet olma bilincinde bir nesli yetiștirmek için gereken pedagojik yaklaşımın belirleyicisi olarak sosyolojinin bakış açısını temel alan erken Cumhuriyet dönemi eğitim anlayışı çeşitli uygulamaları ve bu uygulamaların ilkelerini ve içeriğini izah eden ilk eserlerin yayımlandığı bir dönemdir. $\mathrm{Bu}$ çalışmada Hasan Zeynettin'in, Ziya Gökalp'ın sosyolojik olarak eğitim anlayışından ve kaynaklarından hareketle Millî Pedagoji ve Türk İçtimaiyatı adlı eseri dönemin sosyolojik bakış açısını ve pedagoji anlayışını yansıtış biçimi ile ele alınacaktır.

Anahtar Kelimeler : Hasan Zeynettin, Ziya Gökalp, Eğitim Sosyolojisi, Pedagoji Tarihi 


\title{
A Pioneering Work on Sociology and Pedagogy in the Construction of the Republican Generation: Hasan Zeynettin Akkök and His Book "National Pedagogy and Turkish Sociology"
}

\author{
Dr. Yeliz Okay
}

First received: 16.07 .2019

Accepted: 22.07 .2019

\section{Citation:}

Journal of the International

Scientific Research (IBAD)

Volume: $4 \quad$ Issue: 2

Pages: 453-459 Year: 2019

Session: Summer

This article was checked by Turnitin. Similarity Index 05\%

${ }_{1}^{1}$ Türkiye, yelizakinokay@gmail.com ORCID ID 0000-0001-8868-9436

* Corresponding Author

\begin{abstract}
The understanding of education in the Republican period, which is shaped around the idea of national society and national identity, has been shaped by the principles of Sociology and Pedagogy scientifically on sociocultural foundations. The Republican Era, Ziya Gökalp's formation of a folk ideal shaped by national consciousness under the umbrella of national identity and national culture provided the determination of the principles of national education in this direction. Early education in the Republican period, which is based on the perspective of sociology as the determinant of the pedagogical approach needed to raise a generation in the consciousness of being a nation, is a period in which the first works explaining the various applications and the principles and content of these practices are published. In this study, Hasan Zeynettin's work called National Pedagogy and Turkish Internal Therapy, which is based on Ziya Gökalp's sociological understanding of education and its sources, will be discussed in a way that reflects the sociological perspective and pedagogical understanding of the period.
\end{abstract}

Keywords: Hasan Zeynettin, Ziya Gökalp, Sociology of Education, History of 


\section{GİRIŞ}

Çok uluslu imparatorluk yapısından ulus devlete geçiş sürecinde toplumsal yapıda meydana gelen değişimler ve değişimlerin yarattığı sosyal sorunların çözümünün merkezine Sosyoloji disiplinini koyan Ziya Gökalp'ın etkisi, doktrin olarak millî kültür ve kimlik esasına dayalı toplumun oluşum koşullarını Yeni Hayat görüşü olarak şekillendirmiştir. Bu görüş kültürel milliyetçilik esasına dayalı olarak toplumsal yaşamın her alanında yenileşmeyi ve Halka Doğru esaslarını içermektedir. Millî anlayışı esas alan Ziya Gökalp doktrininin eğitime ilişkin boyutu millî kimliğin tüm toplumsal görünümünü bünyesinde taşıyan ideal vatandaşı yetiştirmek gayesi ile biçimlendirmiş̧ir. Gökalp bunu sağlamak için de millı̂ eğitimin pedagoji ve sosyoloji esaslarına göre şekillenmesi amacıyla kaleme aldığı fikir yazılarında eğitimin sosyokültürel temelleri meselesini tartışır. Ziya Gökalp, kendi döneminde içinde yaşadığı coğrafyanın toplumsal yapısının sosyal, siyasal, ekonomik ve kültürel koşulların Türkçülük anlayışı çerçevesinde olgunlaşması gereğine odaklanırken millî olgusunu esas aldığı kadar Durkheim gibi Batılı sosyologların toplum ve toplumsal meseleler hakkındaki görüşlerini de benimsemiştir. Gökalp'ın toplumsal yapıda meydana gelen ve kimliği şekillendiren sosyokültürel değişim ile eğitim arasındaki bağlantıya sosyolojik perspektiften bakarken Durkheim Sosyolojisi'nin temel kavramları ve ilkelerini hareket noktası seçtiğini söylemek mümkündür.

Eğitime, bireyin toplum içinde sosyalleşmesi olarak bakan Gökalp, eğitim ile kültür arasındaki ilişkinin gereği üzerinde dururken, Batı'da eğitim ile kültürün, birbirine uygun olduğunu ve örgün eğitimin, örgün olmayan eğitimin izini takip ettiğini ancak yerelde durumun farklı olduğunu, bu farklılı̆̆ın da toplumsal bunalımlara yol açtığını ifade eder (Tezcan, 1986, s.26). Ziya Gökalp, örgün eğitim ile alınan yabancı fikirlerin, örgün olmayan eğitim ile alınan millî duygulara zıt olduğu için; eğitim/kültür ikiliğinin ortaya çıktığını, bu iki kavramın birbiriyle ilişkili olmakla birlikte uyumlarının gerçekleşmediğini ifade ederek Kültürel Türkçülüğün amacını, eğitimimizi, bir yandan milletlerarası uygarlığa, diğer yandan millî kültüre intibak ettirmek olarak tanımlar (Gökalp, 1973, s.36).Gökalp'ın Yeni Hayat görüşünün doktrin olarak inşasından sonra başta Ömer Seyfettin olmak üzere gerek halka idealin ulaşması gerekse kurumsallaşması için çeşitli fikir yazıları kaleme alınırken eğitim ve yaşamın tüm alanlarında çeviri yazılar ve kitaplar kaleme alınmaya başlanmıştır. 1914'de Ömer Seyfettin'in kaleme aldığı Mektep Çocuklarında Türklük Mefkûresi başlıklı yazının bölümlerinden biri Bir Çocuk Nasıl Türk Milliyetperveri olur? (Ömer Seyfettin, 2016, s.461) ara başlı̆̆ını taşır. Kültürel Türkçülüğün tasavvurundaki millî kimliği eğitim müfredatında nasıl biçimlendirmek gerektiği üzerine olan bu yazı millî mefkûre fikri çevresinde şekillenmiştir. Balkan Savaşı sonrası toplumsal ve siyasal çözülme ile başlayan Cumhuriyet'in erken dönem eğitim ve kültür politikalarında da etkisi süren Ziya Gökalp doktrininin geniş bir etki alanı olduğunu dönemin kitaplarında ve süreli yayınlarında görmek mümkündür.

Gökalp düşüncesi ile biçimlenen eğitim politikalarını haklılaştıran erken Cumhuriyet dönemi yerli yayınları, millî mefkûrenin toplumsal yapıda örgütlenmesi ve kabulü ve millî kimliği taşıyan milletin mensubu olan bireyin eğitiminin felsefî, sosyolojik ve kültürel esaslarını belirlemeyi ve kalıcı hale getirmeyi amaçlamışlardır. Sosyoloji disiplini gibi pedagoji de Batı kaynaklı olmasının yanında ortaya çıktıkları Batı toplumunun sorunlarını çözmek üzere kuramsal nitelikli şekillenmiştir. Disiplinin uygulama alanının eğitim ortamı olduğu düşünüldügünde devletlerin eğitim politikaları geliştirme sürecinde bu disiplin ile arasındaki ilişki makul olarak algılanabilir. Dolayısı ile her ülkenin eğitim sistemindeki farklılıkların farklı birey imgesi inşa ettiği düşünüldügünde, toplumdan topluma kuramsal genel ilkeler bağlamında olmasa da ilkelerin sahada yorumlanışı ve yöntemleri görece olabilir. Küreselleşme ve güncel koşullar tesirinde geliştirilen eğitim modellerinin giderek bu görece durumu ortadan kaldırması sosyolojik anlamda başka bir çalışmanın konusudur ancak sosyoloji, pedagoji, siyaset bilimi disiplinlerini ortak çalışma sahası olarak benimsemiş araştırmacılar 1914 ve 1938 dönemi Türkiye'si için değerlendirme yaparken dönemin koşulları içinde geliştirilen sosyal politikalara getirdikleri tenkitlerde ulus devlet inşa sürecinde idealize edilen toplumun ortaya koymak istediği nesli zihinsel şemalarında taşıdıkları kodlar ve bugün temsil ettiklerini düşündükleri kesimlermiş gibi sosyal ve tarihsel gerçeklerden bağımsız yorumlamakta ısrarcı tavır içindedirler. Millî pedagoji kavramına getirilen eleştiriler Batı ile mukayeseli, disiplinlerarası pedagoji tarihi çalışmalarının eksikliği ya da görmezden gelinmesi ile pedagojiye güncel yaklaşımları sadece eğitim modeli geliştirmek olarak 
eğitimcilerin sahası olarak yorumlanması kaynaklıdır. Tabii olarak bir başka neden de ise "Millî kelimesinin Türk kelimesi ile aynı cümlede kullanıldığ 1 anda belli kesimler üzerinde yarattığ 1 tesirdir" demek mümkündür. Bu anlamda Balkan Savaşı sürecinde gerek devletin gerekse Türk kimliğine sahip insanların yaşadıklarını toplumsal hafizanın derinlerine itmek ya da görmezden gelmek yoluyla "ulus devlet inşa sürecinin etnik politikası" söylemine dönemin eğitim yaklaşımlarını boğmak sağlıklı bir bakış açış olmadığı gibi dönemin bir diğer gerçeği Osmanlı İmparatorluğu'nu oluşturan çok kültürlü etnik yapının yaşadıkları özgür coğrafyada kendi kültürel kimliğine dair toplumsal belleğinde koruduğu ve aktardığı kodları aynı ulus-devlet dalgası içinde kendi bağımsızlığı yolunda kullandığını inkâr da nesnel bir yaklaşım değildir. Tüm bunların sonucunda millî pedagoji ve millî eğitim kavramına tıpkı eğitimde bireysel farklılıkların göz önünde bulundurulması ilkesi gibi ya da Türk Sosyolojisi'nin Türk toplumunun toplumsal yapısına ilişkin söylediği sözlerde yerli olgularla hareket etmesi gereği gibi Psikoloji de bir zeka ölçeğinin toplumun kültürel yapısına uyarlanması gereği gibi bir zaruret olarak algılanması meseleyi daha çıplak gözle görmeyi sağlayabilir.

Pedagoji ile ilgili erken Cumhuriyet dönemi literatüründen bahsetmek mümkündür ve sadece millî pedagoji değil Pedagoji tarihine ilişkin çok erken dönemden itibaren Batı'dan yapılan çevirilerin varlığı dikkati çeker. Aynı zamanda Türk toplumu ve millî eğitime ilişkin kaleme alınan fikir yazılarında Batılı pedagogların ve düşünürlerin görüşlerine yapılan atıflar "millî eğitimin" sadece ulus devlet inşası yolunda bir araç olarak pedagojinin de imkânlarını kullandığı yönündeki ifadelerin tekrar düşünülmesi gereğini ortaya koyar. Eğitimde kuramsız bir uygulamanın işe yaramayacağını çok iyi bilen Nafi Atuf Kansu, tarihsel süreç içinde eğitim düşüncesinin evrimini incelemiştir (Kansu\&Kansu, 2011, s.9). Tolstoy'un eğitimci kişiliğini kaleme aldığı Tolstoy: İptidai Muallimi 1919 yılında yayımlanmıştır. Yine Fransız eğitim düşünürü Demolen (1914)'in, Alman Fröbel (1916)'ın, düşüncelerini de tanıtan kitapları kaleme alan Kansu, ardından ülkemizde ilk derli toplu eğitim düşünürleri tarihi kitabı olan 347 sayfalık Fenn-i Terbiye Tarihi (1918)'ni yayımlar. Bu kitap 1928'de aynı adla, 1929'dan başlayarak Pedagoji Tarihi adıyla 1952'ye kadar yeni harflerle defalarca basılıp ögretmen okullarında ve köy enstitülerinde okutulmuştur. Ayrıca Kansu'nun kaleme aldığı millî eğitim meselesine ilişkin tüm fikir yazılarında neden "Millî eğitim şarttır ve nasıl olmalıdır?" noktasında Batılı düşünürlerin fikirlerine yapılan atıflar fikri olarak ölçütün ne olduğunu göstermesi bakımından önemlidir. Pedagojinin tarihi yenidir, yeni terbiyenin insiyak yerine düşünceyi, kör tabiat yerine de sanatı koyduğu tarihten başlar (Kansu, 1932, s.3) diyen Kansu, "Maarifimiz" başlığı ile yayımladığı yazılarında Fichte'nin, millî terbiye tarifini alarak neden millî eğitime ihtiyaç duyulduğunu şöyle açıklar: "Fichte, millî terbiyeyi, "Bütün vatandaşlardan aynı menafi ile yaşayan bir vücut teşkil etmektir.” diye izah etmişti Müderris M. Zühdü Bey: “" 1331(1915) senesi Türk iktisad-1 millîsinin en büyük tohum atım senesi, temel merasimi devresidir." diyor. 1331 y1lına millî terbiye yılı diyememekle beraber harbin muallimlerimizi talim ve terbiyede milliyete daha ziyade yaklaştırdığımızı söyleyebilirim. Birçok muallimler çocuklara bir milliyete, bir vatana mensup olduklarını anlatmanın lâzım olduğunu idrake başladılar. Geçen sene Anadolu'muzun büyük bir şehrinde ibtidai mekteplerini gezmiştik. Çocukların ancak yüzde beşi milletini biliyordu. Çoğu millet yerine dinini veyahut doğduğu memleketi söylüyordu. Payitahtı bilmeyen mekteplere de rastladık.Çocukları milliyet, vatan, din vahdetleri etrafında toplamak lâzımdır"(Kansu, 1916, s.110).

Öğretmen okulları için ders kitabı olarak İbrahim Alaeddin Gövsa tarafından hazırlanmış Rûhiyat ve Terbiye ise 1929 yılında, kısmen tercüme, kısmen yazarın öğretmen okullarındaki hocalık tecrübelerinin mahsulüdür(Çetin, 1996, s.160). Gövsa da bu eserinde millî eğitimin neden gerekli olduğunu şöyle ifade eder; "Bilhassa Türk çocukları ve Türk mektepleri için irade terbiyesi belki hiçbir millete kıyas edilemeyecek derecede ehemmiyeti haizdir. Büyük muharebelerden, büyük inkılâplarından sonra türlü müşküllere rağmen hür ve müstakil yaşamaya, asırlardan beri kendini geçen medeniyet ve terakki cihanına süratle yetişmeye azmetmiş bir milletin evladı her şeyden evvel iradeli olmaya muhtaçtır. Dört tarafı siyasi ve iktisadi düşmanlarla mahsur olan kıymetli bir vatanın üstünde ancak kuvvetli şahsiyetler temel tutabilir"'(Gövsa, 1929, s.110).

Millî Pedagoji ve Türk İçtimaiyatı adlı eser bu anlamda ulusun inşasında çocuğun sosyopolitik olarak öneminden yola çıarak eğitimi ve millî kimliği kazanma süreçleri yönüyle de bir değerlendirme olarak görülebilir. Bu çalışmada Türk toplumu ile ilişkili olarak nasıl bir pedagojik anlayışla hareket edilmesi gerektiğini ve neden pedagoji konusunda yaklaşımda millî bir anlayış benimsenmesi gerektiğini çeşitli 
başlıklarla ele alan Hasan Zeynettin Akkök'ün Millî Pedagoji ve Türk İçtimaiyatı adlı eseri pedagoji çalışmalarının sosyolojik ve tarihsel nedenlerle ilişkilendirilmesinin bir örneği olarak ele alınacaktır.

\section{SOSYOLOJI VE PEDAGOJİ AÇISINDAN HASAN ZEYNEDDİN AKKÖK'ÜN KITTABI MILLÎ PEDAGOJI VE TÜRK İÇTIMMAIYYATI ADLI ESERİ}

Cumhuriyet Dönemi'nde eğitim sosyolojisi ve pedagoji alanında yazılan öncü esrelerden biri de Hasan Zeynettin tarafından kaleme alınan Millî Pedagoji ve Türk İçtimaiyatı adlı kitaptır. Kitabın kapağında yer alan bilgiye göre İstanbul'da 22. Mektep Muallimi olan Hasan Zeynettin'in -arka kapakta yer alan bilgiye göre de- yakında çıkaracağı kitaplar Cumhuriyet Türkiye'si İçin Terbiyevî Heyecanlarım(*), Yeni Türk Dili ile Terbiyevî Şiirler, Büyük Türk Çocuğu (Terbiyevî Roman) olarak sıralanmıştır. Bütün bu yayınlardan Hasan Zeynettin'in hem Cumhuriyet'in yaptığı yeniliklere bağlı hem de pedagoji alanıyla yakından ilgili olduğu anlaşılmaktadır. Bu kanıyı doğrulayan bir başka ibare yine kapakta yer almaktadır ki bu eserin "Büyük Gazi'nin Büyük İdealine Hizmet" olduğu belirtilir.

Kitabın üst başlığı 'Mefkûrevî Pedagojik Cereyanlar 1'dir. Hasan Zeynettin "Millî Pedagoji ve Türk İçtimaiyatı'ni Niçin Çıkarıyorum?" başlıklı sunuş yazısında ülkede millî bir pedagoji anlayışıyla ilgili bir eser bulunmadığ bu dolayısı ile 'inkılâbın ruhu olacak millî ve terbiyevî eserlerle milletin millî ülküsüne daha şuurlu koşacağını' ve bu eserler Türk yurduna borçlu birçok olduğu birçok görevlerden birini yerine getirmiş olacağını yazar.

"Millî Pedagoji Nedir ?" başlıklı ilk bölümde bu kavramı tanımlayan Zeynettin Akkök, millî tesirlerden doğan bütün eserlerin Millî Pedagoji olduğunu; 'ilmî' bilimsel pedagojide tabiat, insan ya da uluslararası faktörlerin terbiye rolünü üstlenirken; coğrafi Türkiye, manevî Türkiye ve vatan ve milletseverlerin yeni nesillerine 'vatanî, cumhurî ve harsî' etkilerinin de Millî Pedagoji'yi meydana getirdiğini ifade eder (Zeynettin, 1933, s.4) ki uluslar, Millî Pedagoji’ye verdiği önem oranında ekonomik zaferlerini belirlemiş olurlar diyerek (Zeynettin, 1933, s.5), milli pedagoji kavramının neden milli ölçütler ile belirlenmesi gereğini açıklar. Zeynettin Akkök'e göre dünyadaki en büyük ırk Türk ırkıdır ve bunu Millî Pedagoji'ye borçludur ve İstiklâl Harbi'nin sonuçları Millî Pedagoji’yi uygulamayı bir kere daha zorunlu kılmıştır(Zeynettin, 1933, s.6). Millî Pedagoji'nin amacı ise Cumhuriyet Türkiyesi’nin kalkınmasına yol açmak ve Cumhuriyet çocuklarının ahlâken değerbilir, iktisadî olarak faal-üretken, hukuken demokrat, itikaden hoşgörülü, siyaseten cumhuriyetçi ve hayaten iyimser yapmaktır der ve dönemin neslinden beklenenlerin tarifini yapar. (Zeynettin, 1933, s.6). Hasan Zeynettin Millî Pedagoji'nin Sosyoloji ve Psikoloji ile ilişkisi bulunduğunu dile getirerek kendisinin bu disiplinler üzerinde yayınlar yapacağını söyleyerek millî kültürü, millî istidadı, millî inkılâbı ileri götürecek eserleri sosyologların yazması gerektiğini ifade eder. (Zeynettin, 1933, s.6-7)Bir anlamda erken cumhuriyetin üzerine oturduğu bilimsel temellerin sosyoloji, psikoloji ve pedagoji üzerine oturduğunu ifade etmiştir.

Hasan Zeynettin izleyen bölümde İlmî Pedagoji ile Millî Pedagoji arasındaki farklara değinir. Buna göre İlmî Pedagoji beynelmileldir ve vatanı yoktur, ulustan ulusa geçer, Millî Pedagoji ise ulusaldır. Ulusların toplumsal krizlerinden doğduğu için bir ulustan diğerine aynı şekilde geçmez. İlmî Pedagoji rasyonel, bilimsel ve deneysel yollarla ortaya çıkar ancak Millî Pedagoji ulusal bilinçten yola çıkarak meydana getirilir. İlmî Pedagoji; iradî, bedenî, hissî, ahlakî, iktisadî, hukukî ve benzeri düşünceleri meydana çıkarırken Millî Pedagoji bunları arttırır ve takviye eder. (Zeynettin, 1933, s.16-17) Zeynettin'in üzerinde durduğu ve tüm kitabında ele aldığı bu ayrım özünde pedagoji, gelişim psikolojisi ve eğitim disiplinlerinde yapılan çalışmaların kültürel farklılıklar nedeni ile terminolojide millî olarak ifade edilmese de Batı kaynaklı programların, yöntemlerin ve ölçek nitelikli materyallerin Türk toplumsal yapısına uyarlanması gereğinin çok erken dönemde ifadesidir. Zeynettin, siyasal olarak ırk üzerinden bir neslin kimliğini tanımlamışsa da bu durumu özünde sosyoloji disiplini dahil tüm disiplinlerin toplumsal yapıya uygun kuramsal temelli uygulamalarla toplumsal sorunlara çözüm araması gereğini günün koşullarında ifade ediş biçimi olarak kabul etmek mümkündür.

Hasan Zeynettin daha sonra pedagojik anlayışın etkilendiği çevresel faktörler üzerinde durur. Çocuğun doğar doğmaz evini, ailesini ve vatanını gördüğünü ve bunların millî terbiyede en büyük etken olduğunu belirterek bir anlamda toplumsallaşmanın ön koşulunun sosyal çevre olarak işaret eder ki bu pedagoji de evrensel nitelikli bir kabuldür (Zeynettin, 1933, s.30-32). Millî Pedagoji'den en büyük etkenlerden 
birinin de sosyal çevre olduğuna değinen Akkök (Zeynettin, 1933, s.38-42) daha sonra Millî Pedagoji'nin nasıl incelenip araştırılması konusuna temas ederek bunda özellikle Sosyoloji'nin rolünü vurgular. Akkök'e göre sosyolojik açıdan incelenmeyen bir ulusun kendi Millî Pedagojisini sağlıklı bir biçimde ortaya koymasına olanak yoktur dolayısıyla Türk Sosyologlarına büyük görev düşmektedir.(Zeynettin, 1933, s.58). Hasan Zeynettin'e göre sosyolojik olarak ulusların ortak özellikleri çok azdır dolayısı ile bir ulusu diğer uluslardan ayıran toplumsal özellikleridir ve Millî Terbiye Türk Sosyolojisi'nden doğacaktır.(Zeynettin, 1933, s.58). Kültürel Psikoloji (harsî ruhîyat) ve Kültürel Pedagoji kavramlarına da değinen Akkök özellikle kadınların toplumdaki yerini yükseltmek açısından Millî Pedagoji’ye ve Sosyoloji’ye görev düştügü kanısındadır. (Zeynettin, 1933, s.74-75).

Hasan Zaynettin, Milli Pedagoji İçin Neler Gereklidir? başlığı ile kaleme aldığı bölümde Ziya Gökalp'in Kültürel Türkçülük doktrininin Halka Doğru prensibine uygun detaylar ile konuyu açıklarken geçmişte millet bilincinin oluşmasının önündeki engel olarak ümmet anlayışının hakim olmasını işaret eder (Zeynettin, 1933, s.51). Zeynettin, Millî Pedagoji disiplininin öncelikle halkın eğitim anlayışını kavrayıp milli terbiye için halkın anlayışına yönelmesinin gereği üzerinde durur. Ayrıca Yeni Hayat görüşünün bakış açısına uygun olarak dilde Arapça ve Farsça tesirinden kurtulmuş bir eğitim terminolojisinin önemini de vurgular ki bu sosyoloji disiplini ilkeleri ile şekillenmiş olan Ziya Gökalp anlayışının erken cumhuriyet döneminde etkisinin sürdüğünün de göstergesidir. Hasan Zeynettin, Millî Pedagoji'nin ancak halk duygusunu yücelten halk edebiyatının ürünlerinin anlaşılması ile halkın sosyal yapısının değişkenlerini kavrayabileceğini söyler(Zeynettin,1933, s.52). Yunus Emre'nin, Karacaoğlan'in eserlerinin ve dilinin anlaşılmasının ve edebiyattaki avam-havas ikiliğinin kalkmasının Türk halkının gündelik hayatta kullandığı dilin Millî Edebiyat'a da hâkim olmasının Millî Terbiye için olmazsa olmaz olduğunu ifade eder (Zeynettin, 1933, s. 53). Millî Pedagoji için bir diğer önemsediği değişken de Millî tarih bilincidir. Zeynettin Akkök, İslamiyet öncesi Türk Tarihi'nin ve geleneksel Türk kültürünün zenginliğinin gençlere aktarılması gereken kültürel kodlar olduğunu ve bu sayede millî bir şuurun gençlerde yerleşebileceğini söyler ve son olarak Millî Müze'nin millî terbiye için gereği üzerinde durur. Türklüğe ait tüm kültürel kodları içeren İslamiyet öncesi döneme ait kültürel zenginliğin bu müzelerde sergilenmeleri gerektiğini vurgular (Zeynettin, 1933, s. 54). Millî Pedagoji'nin sosyolojik anlamda amaçları üzerinde de durur. Türk toplumsal yapısının oluşumunda birincil dereden önemli gördüğü Türk ailesinin toplumsal hayat içindeki görünümünü yükseltmek amacını ilk amaç olarak vurgular (Zeynettin, 1933, s. 71). Bu noktada Zeynettin, kadının toplumsal temsilinin ve kimliğinin Türk toplumunda görünür olmasının gereği üzerinde durur. Millî Pedagoji’nin öncelikle kadını merkeze koyması gerektiğini vurgularken millî terbiye feminist bir terbiyedir demesi dikkati çeker. Kadına ve kız çocuklarına toplumda varlık gösterebilecekleri siyasal ve sosyal hakların verilmedikçe ve toplumsal hayatın içinde kadın görünür olmadıkça toplumun ilerleyemeyeceğini vurgular (Zeynettin, 1933, s. 72). Millî Terbiye'nin kadını, devleti, milleti ve aileyi yükseltmesini toplumsal amaçları olarak sıralayan eğitimci, Türk kadınının üç temel toplumsal sistem olarak sıraladığı devlette, ailede, millette merkezi konumda olduğu takdirde gelişebileceğini vurgular. Kadının cumhuriyetten önceki konumunun Türk toplumsal yapısının gerçeği olmadığını ve Arap toplumunun gerçeği olduğunu kadının gerçek millî kimliğine ulaşması için devletin gerekli hakları teminat altına alması gereğinin üzerinde durur (Zeynettin, 1933, s. 72). Kadının güçlü bir kimliğe sahip oluşunun çocuğun ilk sosyalleşme basamağ gerçekleşebileceğini söyleyen yazar, kadınları toplumsal hayatın gereklerine göre yetiştirmek gereği üzerinde durur. Hasan Zeynettin, millî iktisat bilincini de veren bir eğitimin toplumsal hedeflere ulaşmada önemli olduğunu çocuğun eğitiminde milli bilinç içinde tasarruf ve yerli olanın kıymetli olduğunun öğretilmesinin önemli olduğunu vurgular. Kitapta görsel malzeme olarak "Türkiye'de Millî Pedagoji'nin Ölmez Bir Dâhisi" altyazısıyla Atatürk ve "Millî Pedagoji ve Türk İçtimaiyatının(sosyolojisinin) Biricik Hâmisi" altyazısıyla İnönü ve "Türkiye'de ilk Millî Mürebbi" altyazısıyla Türkiye'de Sosyoloji'nin kurucusu Ziya Gökalp resimleri yer alır (Zeynettin, 1933, s.41).

\section{SONUÇ}

Hasan Zeynettin'in eğitimci olarak Milli Pedagoji ve Türk İçtimaiyatı adlı eseri erken cumhuriyet döneminin eğitimci profilini ortaya koyması bakımından olduğu kadar eğitimin sosyolojik ve pedagojik olarak dönemin siyasal ve sosyal koşullarında nasıl tasarlandığı hakkında fikirler vermesi bakımından önemlidir. Pedagoji gibi Batı kökenli bir disiplinin neden millî olarak biçimlenmesi gerektiğini 
sosyolojik nedenlere dayandırarak açılayan Zeynettin Akkök, sosyolojiyi, millî pedagojinin kaynağı olarak görürken bunu toplumsal yapıya ilişkin nedenlerle açıklar. Hasan Zeynettin'in bakış açısında bir diğer önemli nokta ise Kültürel Türkçülük doktrininin fikir babası ve Türk Sosyolojisi'nin kurucusu Ziya Gökalp'ın toplum düşüncesi çerçevesinde millî pedagoji anlayışını ortaya koymuş olmasıdır. Bu bakış açısı Atatürk Dönemi toplumsal yapı tasavvurunda ölçüt kabul edilen Ziya Gökalp'ın topluma dair fikirlerinin etkisinin kitabın kaleme alındığı dönemde de sürdüğünü göstermesi bakımından önemlidir. Eğitimci Akkök, Millî Pedagoji’nin toplumsal amaçlarını milli eğitimin sosyolojik esaslar dikkate alınarak planlanması ile gerçekleştirebileceğini vurgularken toplumsal yapıda çeşitli toplumsal kurumlar aracılığ olduğunu belirtir. Tüm sosyalleşme süreçlerinin bireyin Türk millî kimliğini edinmiş olarak yetişmesini hedeflediğini vurgularken bunun bilimsel yöntemlerle planlanması için pedagoji ile sosyolojinin disiplinler arası çalışması gereğine değinen yazar; kadın, çocuk politikalarının da Millı̂ Pedagoji ve Sosyoloji perspektifinden belirlenebileceğinin altını çizer. Hasan Zeynettin'in üzerinde israrla durduğu noktalardan hareketle halkın kültürel kodlarının esas alınarak avam-havas ikiliğine yol açan tüm değişkenlerin gözden geçirilmesi ve dilde sadeleşme gibi gereklerin yerine getirilmesi toplumsal yapıda egemen olan yabancılaşmaya yol açan ne kadar sosyal gösterge varsa Türk millî kimliği esaslarına göre yeniden düzenlemesi gibi o dönemin güncel meselelerinin düşünsel yapıyı şekillendirdiğini söylemek mümkündür. Hasan Zeynettin'in bakış açısı ve kaleme aldığı Millî Pedagoji ve Türk İçtimaiyatı adlı eser kimliğin inşası ve toplumun kültürel kodlarına dönüş yoluyla millî bilincin aktarımı gibi siyasal-sosyal yapıya uygun nitelikler taşıyan neslin yetişmesinin yöntemini ortaya koyan dönemin diğer eserleri ile aynı niteliktedir. Sosyoloji disiplininin millî pedagoji anlayışının biçimlenmesinde önemsenmesi ve Ziya Gökalp düşüncesi ölçeğinde hareket etmesi dönemin hâkim Türkçülük akımının eğitim düşüncesini yansıtması itibarıla önemlidir.

\section{NOTLAR}

(*) Bu kitap 1935 yılında Cumhuriyet Türkiye'sine İçin Terbiyevî Heyecanlarım adı ile 1935 yılında basılmıştır. İstanbul: Bozkurt Matbaas1.

\section{KAYNAKÇA}

Çetin, A. (1996). İbrahim Alaeddin Gövsa. TDV İslâm Ansiklopedisi (DİA) içinde. (c. 14, ss. 158-160). İstanbul: Diyanet Vakf1 Yayınları.

Hasan Zeynettin[Akkök].(1933). Milli Pedagoji ve Türk İçtimaiyatı. İstanbul: Necm-i istikbal Matbaası.

İbrahim Alaeddin[Gövsa].(1929). Ruhiyat ve Terbiye. İstanbul: Muallim Mektebi Kitapları.

Kansu, M.A. Kansu. I.(2011) I. Cumhuriyet Eğitim Devriminin Mülkiyeli Mimarı Nafi Atuf Kansu Yaşamı ve Yazıları 1890-1949. Ankara: Mülkiyeliler Birliği Yayınları.

Nafi Atuf[Kansu].(1932). Pedagoji Tarihi. İstanbul: Muallim Mektebi Kitapları.

Ömer Seyfettin (2016). Bütün Nesirleri (haz. Nazım Hikmet Polat). Ankara: Türk Dil kurumu Yayınları.

Tezcan, M.(1985). Eğitim Sosyolojisi. Ankara: Ankara Üniversitesi Eğitim Bilimleri Fakültesi Yayinları.

Ziya Gökalp. (1981). Makaleler V. (haz.Rıza Kardaş). Ankara: Kültür Bakanlığı Yayınları.

Ziya Gökalp. (1982). Makaleler VII. (haz. Rıza Kardaş). Ankara: Kültür Bakanlığı Yayınları. 